\title{
MUSEERNA OCH TIDSANDANS FÖRÄNDRING
}

\author{
Göran Rosander
}

Att sla fast vad 'tidsandan' innebär och att folja dess variation erbjuder vissa svårigheter, som kommer att framgå. Att däremot fastställa tidpunkten för de svenska museernas grundläggande förändring av verksambeten, en ny svensk museologi, är däremot enkelt. Det finns ett symboliskt datum: 1 februari 1962. Den dagen tillträdde Harald Hvarfner som landsantikvarie i Norrbotten.

$I$

Harald Hvarfner (1927-1975) var dubbellicentiat (Nordisk och jämförande folklivsforskning och Nordisk och jämförande fornkunskap). I början av 50-talet fick han anställning på Fornminnesavdelningen vid riksantikvarieämbetet och blev snart ledare av den s.k. Sjöregleringsavdelningen, en nyupprättad enhet, som svarade för arkeologiska inventeringar och utgrävningar inför kraftverksutbyggnader, snart också för etnologiska undersökningar. ${ }^{1}$

Hvarfner sökte 1961 tjänsten i Luleå och fick den alltså. Han smidde stora planer och erhöll från 1964 medel från Ecklesiastikdepartementet "för försöksverksamhet», dvs. regional undervisning och utställningsverksamhet; han ville att museet skulle arbeta decentraliserat. Två museilektorer, Claes-Göran Forsberg och Lisbeth Malmberg, anställdes. Yrkeskategorin fanns då bara vid några museer i storstäderna. Snart fick också andra museimän kortare förordnanden inom försöksverksamheten, också regionala institutioner bidrog med pengar. $^{2}$ Norrbotten blev med detta ett experimentfält med en fortsatt nyskapande och expanderande verksamhet. Redan 1963 tillkom utställningar som sändes ut till skolorna, något som då var ovanligt på länsmuseinivå.

För att fullborda Hvarfners biografi, blev han 1970 stadsantikvarie i Stockholm. Den 1 september 1973 tillträdde han som styresman för Nordiska museet, men avled $\mathrm{i}$ januari 1975. Han företrädde också på dessa tjänster en seriös, fackorienterad och delvis nyskapande museologi, fjärran från jippon och lättköpta publika segrar. Många såg i honom ett slags den svenska museivärldens Kennedy. Sin museologiska ideologi framlade han i debattboken 70-talets museum, en antologi för vilken han var primus motor.

Jag har uppehållit mig så pass utförligt vid den hvarfnerska verksamheten därför att jag alltså anser att museiväsendets förändring börjar med honom. Min historieskrivning startar där, för en generation sedan. Den föregående perioden, från 
14 landsantikvariereformen vid 1930-talets mitt, uppfattar jag - något schablonmässigt, det medges - för museernas del som enhetlig, reformfri och tämligen opåverkad av tidsandan; man arbetade för det mesta vetenskapligt och föga spektakulärt. Antagligen har ett generationsskifte i någon grad del i förändringen: de på 30-talet tillsatta unga landsantikvarierna går på 60talet i pension.

\section{II}

Vi är alla medvetna om att olika tider har sina specifika värderingar, grundade på aktuella idéer och ideologiska tankefigurer. Den generella atmosfären i samhället, de förhärskande stämningarna och åsikterna, tidsandan, ändras. Nya tankar förs fram, slår rot och internaliseras kollektivt, de gamla blir ointressanta och skjuts i bakgrunden eller försvinner.

Men vad ingår i tidsandan, om vi granskar den närmare? Begreppet - efter Zeitgeist, antagligen uppfunnet av Goethe, lanserat av Hegel och i Sverige tidigast använt av Tegnér 1817 - är ej analytiskt utan snarare en meningstotalitet som alla vet vad den innebär, men ingen kan definiera. Man kan därför också kalla det ett säckbegrepp. Antagligen har varje individ sin uppfattning av vad som ingår i tidsandan, men förmodligen finns det i varje nation en någorlunda samstämmig uppfattning i stort. Jag har blott lyckats hitta en enda vägande analys av den hyperkomplexa termen, en skrift av Svante Beckman $^{3}$. Det följande är därför till stor del en tentativ diskussion.

Uppenbarligen är värderingar det viktigaste inslaget i tidsandan, vissa värderingar som trängt igenom de flesta områden i samhället och vars tillämpning av de flesta uppfattas som «sunt förnuft». Besläktat med detta är «allmänna opinionen» och «rådande världsbild». Värderingar av den typ vi här talar om härrör från ideologier $\mathrm{i}$ betydelsen samhällsåskådning. Med SvenEric Liedman ${ }^{4}$ kan vi säga att en ideologi är någorlunda konsistent och innehåller antaganden om verklighetens beskaffenhet samt värderingar och, inte minst, handlingsnormer. Den manifesteras vanligen i texter. Ideologier behöver inte nödvändigtvis vara politiska; miljörörelsen och det ekologiska tankemönstret var i begynnelsen ett bra exempel på detta. De innehåller som regel föreställningar om hur det goda samhället skall uppnås och önskar styra människor dit. Därmed är sagt att ett konkret maktintresse oftast finns involverat $\mathrm{i}$ ideologierna.

Filosofen Louis Althusser ser ideologierna som lierade med "statsapparaterna" kyrkan, rättsväsendet, skolan, familjen osv., som definierar och sätter betingelserna för vår världsbild och därmed påverkar tankemönster, värderingar och hållningar. Men ideologierna kämpar med varandra, och nya kommer till. I den ständigt pågående processen har dominerande grupper och karismatiska opinionsbildare stor del, i kraft av sitt herradöme över det offentliga samtalet. Politiker och intellektuella går i spetsen, "vanliga människor» följer efter.

Det finns också «fristående» idéer som inte är explicit knutna till rådande ideologier utan framför allt härrör från det vetenskapliga tänkandet, i första hand inom dominerande teoretiska paradigm (positivism, hermeutik, fenomenologi...). För perioden karakteristiska tankemässiga landvinningar ingår alltså i tidsandan.

Ett tredje inslag är något som kan kallas 
metahållningar av olika grad; de har under olika tider olika anslutning i samhället. Grafiskt kan man säga att de rör sig längs en skala med motsatserna som slutpunkter. Exempel är optimistisk-pessimistisk, moralisk-amoralisk, religiös-ickereligiös, inskränkthet-upplysthet, idealistisk-materialistisk. Det rör sig inte om värderingar eller idéer i vanlig mening utan om grundläggande attityder eller ståndpunkter.

Med min terminologi utgör alltså ideologianknutna värderingar, fristående idéer samt hålningar mycket viktiga inslag $\mathrm{i}$ tidsandan. - Beckman ser tidsandan som «en konstellation av dominerande föreställningar och värderingar».

Men - också samhälleliga förhållanden och strukturer påverkar tidsandan, primärt eller sekundärt. Historiska händelser under närmast föregående tid, konjunkturer, rådande social struktur samt teknologiska nyvinningar ger genklang i värderingar, idéer och hållningar. Nya idéer och perspektiv tillkommer. Dessa får i sin tur småningom möjlighet att inverka på samhällsförhållandena i en dialektisk process. Några övertydliga exempel på tidsandan påverkande faktorer från olika tider: krig, geografiska upptäckter, månfärden, depression, ökad invandring, atombomben, databehandlingens genombrott. (Strängt taget kan alla dessa definieras som 'historiska händelser' eller tillstånd.)

Tidsandan känns av, speglas, i rådande generella konstnärliga uttryck, medan avantgarden ligger «i tidsandans framkant» och medverkar till att ändra denna. ${ }^{5}$

Hur fort ändras då tidsandan? Detta växlar uppenbarligen. Många ideologier med sina värderingar är «sega», medan idéer kommer och går. Hållningar kan raskt växla i styrka.
Att tidsandan kan ändra sig hastigt har vi nyss varit vittne till. "Yuppietidens" optimism och konservativa värderingar övergick under konjunkturens tryck i sin motsats.

Min definition av 'tidsandan' blir följande: Den vid varje tillfälle rådande blandningen av dominerande värderingar knutna till ideologier, av allmänt omfattade fristående idéer samt av graden av vissa metahålningar - allt påverkat av samhälleliga strukturer.

Talet om tidsandan kan emellertid också uppfattas som ett slags besvärjelse, ett försök från inflytelserika grupperingar att ge en förklaringsbakgrund med utgångspunkt i egna intressen. Analysen av tidsandan görs ju vanligen i efterhand. Försök att legitimera handlingar och värderingar genom att «skylla på» denna gör sig lätt gällande. Man kan också, med Beckman, fråga sig vilka idéer och vilka gruppers idéer som är representativa.

Nyss nämndes att dominerande vetenskapsteoretiska paradigm bör anses tillhöra tidsandans idéer. Utan att ingå bland dessa intar vid varje tillfälle aktuella teorier inom museifälten - kulturhistoria, estetik och naturvetenskap - en viktig plats i museernas verksamhet. För kulturhistoriens del kan funktionalism, diffusionism, strukturalism, symbolisk interaktionism, generativ metod och kulturanalys exemplifiera mer eller mindre modebetonade tankemönster. Dokumentation, forskning, vård och publik verksamhet påverkas ofrånkomligt, primärt eller sekundärt, utan att tjänstemännen behöver vara medvetna om detta.

Det kan här inte bli tal om att kontinuerligt söka följa tidsandan under de gångna 30 åren. Jag har i stället valt att studera tre korta perioder med ungefär ett decenni- 
16 ums mellanrum; det borde vara möjligt att urskilja vissa förändringar med ett sådant tidsavstånd. Till stor del nöjer jag mig med att "teckna» tidsandan genom att ge ett antal stickord eller ange viktiga händelser som bör ha påverkat denna. Jag erkänner att urvalet kan verka tillfälligt. Empirin hämtas till största delen från huvudstaden och dess kulturhistoriska museer. Skildringen blir ett stycke museihistoria, en historia som knappast skymtar i t.ex. tidskriften Svenska Museer.

\section{III}

Den första period som väljs blir 60-talets mitt och senare del, ett skede som i eftervärldens ljus sannolikt kommer att ses som slutet på «efterkrigstiden». Positivismen med sina objektivitetsideal var på väg ut; förståelse, subjektivitet, osäkerhet börjar prägla det vetenskapliga tänkandet. Studentupproret 1968 kan ses som den vid 50-talets mitt påbörjade ungdomskulturens symboliska höjdpunkt, en revolution mot Gubbväldet. Samma år kom sovjettruppernas kväsande av Pragvåren. Hippierörelsen, drogkulturens tillväxt, protesterna mot Vietnamkriget, morden på Robert Kennedy och Martin Luther King är utländska händelser av dignitet. Insikten om miljöproblemen kom med Rachel Carsons Tyst vår (1962). Här hemma finns en övertro på teknikens möjlighet att lösa problemen och på «social ingenjörskonst». Det s.k. miljonprogrammet för att bygga bort bostadsbristen påbörjades 1965. Av händelser märks t.ex. Kårhusockupationen, protesterna mot den kommersialierade och spekulativa Tonårsmässan och mot Davids Cup-matchen i Båstad mot Sydafrika, allt 1968. I slutet av 1969 kom gruvstrejken i Kiruna, som innebar en utmaning mot LO och det socialdemokratiska partiet. Symbolisk innebörd fick Almstriden i Kungsträdgården våren 1971, då Folkviljan segrade över Myndigheterna. Nej, ingenting blev som förr! Samhället, tidsandan, höll på att förändras - tillräckligt för att vi skall kunna tala om ett trendbrott. 60-talets framtidstro och idyll var över.

Inom museivärlden började ett statligt reformtänkande. Efter 1962 års utrednings totala misslyckande (betänkandet Antikvitetskollegiet), tillsatte regeringen en ny utredning, MUS 65, vars tre betänkanden visserligen kom först 1972-1974, ${ }^{6}$ men vars utspel redan från början livade upp den musei-ideologiska debatten. Inte minst fick den omedelbart igångsatta försöksverksamheten med Riksutställningar betydelse. För många museimän blev institutionen ett hatobjekt, men verksamheten bidrog onekligen till utställningsmediets utveckling.

Det museum som raskast anpassade sig efter de nya signalerna var det ombyggda och 1965 återöppnade Stadsmuseet, som året före fick ny chef: Bo Lagercrantz från Nordiska museet. ${ }^{7}$ Han såg museet som "en estrad bl.a. för opinionsbildning» - en då revolutionerande hållning. Ett par utställningar som väckte ont blod var Spanien 36 (1966; i årsberättelsen karakteriserad som "en avsiktligt proklamatorisk och expressivt monterad materialsamling») och en utställning av affischer från oktoberrevolutionen i S:t Petersburg 1917 (1967). Sistnämnda utställning «väckte avsky på borgerligt håll och utmålades - helt grundlöst - som kommunistpropaganda. [...] I museinämnden frågades det varför utställningsprojektet ej föredragits för nämndens godkännande. Jag svarade att min instruk- 
tion ej innehöll föreskrifter av det slaget. Ej heller i fortsättningen föredrog jag därför sådana ärenden.»

En annan händelse som blåstes upp var en utställning om återanvändning av gasklockan vid Sabbatsberg. Kvällen före öppningen avhölls en fest med rödvin och sallad på museet, något som föranledde löpsedelsrubriken "Orgier på Stadsmuseet». "Avslöjandet» hade gjorts av en kunskapare till stadsfullmäktiges ordförande Eva Remens. Andra tidningar följde upp men fann att orgierna var nog så beskedliga och «ett asflabb spred sig i alla blad». Från detta ögonblick fick Lagercrantz en svuren fiende i ordföranden, något som «ledde till min slutliga undergång». Museet visade också utställningar kring rivningsraseriet, som Staden $i$ retur. Kring temat bildades flera arbetsgrupper sammansatta av intresserade människor ur publiken, mest socialarbetare, samhällsvetare, journalister och arkitekter, men också folk utan professionellt intresse. De arbetade nästan ett år och producerade artiklar m.m. En annan omdebatterad utställning var Du gamla du fria (1969), fotad på en marxistisk historieuppfattning. Den gisslade kapitalet och makten. Museet visade också några externt producerade, livligt debatterade utställningar. Dit hör vandringsutställningen $\ddot{A} n$ sen $d \stackrel{a}{a}$, som behandlade u-landsfrågor och överbefolkning i generella termer. Den var producerad av några chalmerteknologer.

Idén om museet som estrad ledde till att olika lokala opinionsgrupper inbjöds att göra utställningar eller program. T.o.m. Svarta pantrarna fick under ett veckoslut bevisa att de inte bara hyllade våldet utan även drev rättshjälp och skolor i Harlem. Den nya, kritiska teaterform som kallades gatuteatern hade också husrum på museet. Alternativ jul arrangerades.

Trots stöd från många kommunalpolitiker blev Lagercrantz utsatt för krypskytte från stadsfullmäktiges ordförande. Ett försök att fälla honom för övertramp i förhållande till instruktionen avslogs på stadsjuristens inrådan. I samma veva utlöpte hans sexårsförordnande, och det blev turbulens och tidningsskriverier om förlängningen. Lagercrantz tröttnade snart och och avsade sig tjänsten efter ytterligare ett år, trots försök inte minst från kommunala chefstjänstemän att övertala honom.

Händelseförloppet visar oss ett museum (chefen hade starkt stöd hos sin personal) som snabbt anpassar sig till tidsandans mer kontroversiella inslag men kväses. Efterträdare blev alltså Hvarfner, som ju företrädde en helt annan ideologi.

Historiska museet under sin nye, dynamiske chef Olle Isaksson visade 1968 Sune Jonssons foton från augustihändelserna i Prag. Kollegerna såg på tilltaget med stor ovilja: ett dylikt ämne hörde inte hemma där, menade man, men museichefen hade riksantikvariens välsignelse att omskapa Historiska museet till ett slags Sveriges historiska museum, som ju saknas. Han fick småningom stöd för sin sak i museets nya instruktion från 1975; där står att museiutställningarna även får «belysa historia och kulturutveckling inom och utom landet under nyare tid»(i 1980 års instruktion är passusen borttagen). Skrivningen 1975 kan kanske ses som anpassning till tidens "normlöshet». Däremot fick museet inget gehör för sin begäran i petitan om en tjänst för en historiker. - I strävan mot anpassning till den begynnande trenden "det öppna museet» gick institutionen på en mina i form av en famös maskerad. 
18 På Lunds konsthall fick Folke Edwards utställning Underground inhiberas genom kommunens ingripande, eftersom den och dess affisch ansågs utgöra haschpropaganda - detta trots att Edwards erbjöd sig anordna antiknarkinformation.

Moderna museet under Pontus Hulténs ledning bör också nämnas. I utställningar som Hon och Hej stad fanns ett visst subversivt budskap - och de retade upp borgerskapet... Redan 1967 fick museet en verkstad där främst barn kunde få utveckla sin kreativa förmåga - och få utlopp för sitt rörelsebehov. Att främja människors kreativitet var ett klart inslag i tidsandan, en avläggare av flower power-idealet. Stadsmuseet och Nordiska museet följde snart efter med barnaktiviteter, «skumgummimuseet» blev ett barnens glädjeord för en tid. Kanske också föräldrarnas, där kunde de parkera ungarna för att kunna shoppa några timmar $\mathrm{i}$ fred. - Det skall $\mathrm{i}$ sanningens namn sägas att barnen förvisso också erbjöds seriösa utställningsarrangemang.

Något senare, i början av 70-talet, drev Pär Stolpe på Moderna museets filial en verksamhet som hade släktskap med de samhällskritiska utställningarna.

Den begynnande miljörörelsen fick ett nedslag med Naturhistoriska riksmuseets biocidutställning Förgiftar vi naturen? (1966) i anslutning till kvicksilverdebatten 1965-1966. Trots sin karaktär av väggtidning med föga tredimensionell gestaltning fick utställningen en mycket stor publik.

Den enda institution som kan jämföras med Stadsmuseet vad gäller debattutställningar var Riksutställningar med Gunnar Westin som chef. Det började så smått med Multikonst (1967) och Pye Engströms lilla skulpterade kärlekspar som gick att ta isär. Kritiken mot Riksut- ställningar stegrades till storm då Sköna stund kom, 1968 - åter detta magiska årtal! U-landsproblemen behandlades. Utställningen var byggd som ett nöjesfält, spegelbilden av ett genomkommersialiserat samhälle. Konstnärer med grovsatirisk ådra medverkade i utformningen, som Ulf Rahmberg, Lars Hillersberg och Lena Svedberg. Idégivare och huvudproducent var Ulf Lauters.

Det tog hus i helsike. Tidningsanmälningarna radade upp ord som chockverkan, makaber indoktrinering, förvanskning, politisk hötorgskonst, extremism i statsregi - men andra skrev om exposé över u-landsengagemang, samhällsengagerande, riktig och sann. Utbildningsminister Palme fick i riksdagen försvara politiska värderingar i utställningssammanhang, men detta innebar «inte att det allmänna prövar eller ställer sig bakom de åsikter och bedömningar som kommer till uttryck i verksamheten». Antagligen är det nu som tanken på ansvarig utgivare i utställningssammanhang dyker upp.

En av Riksutställningar producerad parallellutställning till Sköna stund, avsedd för mindre orter, var Den rike mannens bord, som tog upp den orättvisa handeln mellan i- och u-land. Den konkretiserade resonemangen i Göran Palms bok En orättvis betraktelse.

Under den behandlade perioden börjar museerna alltså ställa ting under debatt och utöva samhällskritik, helt i överensstämmelse med tidsandan.

\section{IV}

Vad gäller perioden tio år senare, 70-talets mitt och slut, kan det vara lämpligt att först nämna den 1974 i bred enighet 
antagna kulturpropositionen, ett slags kulturens Saltsjöbadsavtal, som efter några år fick så stark genomslagskraft att den måste anses ha påverkat tidsandan. Det viktigaste målet fastslås vara yttrandefrihet. Särskilt myntat på museiverksamheten är bevarandemålet: «att äldre tiders kultur tas till vara». Distribution av «kulturen» och de s.k. eftersatta gruppernas rätt till ett kulturutbud betonas; det finns ett slags teknologiskt tankemönster i propositionen. Viktigt är att det nu existerar pengar i överflöd att förverkliga målen. Detta kommer inte minst museerna till del, de växer kraftigt, framför allt i landsorten. I kulturpropositionens anda tenderar museerna vidare mot att bli «kulturhus" med en livlig programverksamhet, delvis frikopplad från aktuell utställning och museets allmänna verksamhet. Konserter, balett, teater gör sitt intåg.

De tidigare nämnda SOU-volymer som emanerade ur MUS 65 får inverkningar bl.a. på kulturminnesvården - länsantikvarierna - och på centralmuseernas organisation. Minst lika viktigt blir tillkomsten av statens kulturråd med bl.a. en nämnd med tillhörande kansli för området konst, museer och utställningar. Museiområdet får nu för första gången en «ideologiproducent», bestående av dels experter, dels politiskt tillsatta ledamöter. Tyvärr försvann nämnden efter ca tio år vid en omorganisation - dess sista ordförande var Erik Hofrén - men enheten för konst, museer och utställningar består och utgör en kraftkälla med visst inflytande över museipolitiken och museernas verksamhet.

I tidsandan ingår t.ex. miljöfrågor. Den första stora internationella ekologi-konferensen avhölls i Stockholm 1972. Gröna vågen-rörelsen - ordet introducerat 1971 - började växa sig stark, med en förändrad syn på naturens värde, resurshushållningen och de ekologiska sambanden. Tanken på en symbios mellan natur och kultur fanns. Lag om fri abort tillkom 1975. Svältkatastrofer i Afrika, en accelererande arbetslöshet (dock ej i Sverige), tilltagande drogberoende, reaktorolyckan i Harrisburg 1979 - nog fanns det problem! Men i Sverige rådde utvecklingsoptimism.

Ett litet men dock svar på kravet om yttrandefrihet gav Jämtlands läns museum, som ställde ett utrymme, «Fria rutan», till disposition för olika grupperingar. Kanske finns liknande exempel på andra håll.

Yttrandefriheten liksom eftersatta gruppers kulturutbud främjas också genom animerande verksamhet, dvs. strävan att «gjuta ande» inte minst $\mathrm{i}$ museernas ickebesökare, att t.ex. göra dem delaktiga i de kulturella tillgångar som finns lokalt. Museimannen får därför ibland arbeta på fältet. Historiska museet placerade några tjänstemän $i$ en stockholmsförort under längre tid för att levandegöra platsens arkeologiska kulturminnen för lokalbefolkningen. Riksutställningar tog sig an invånarna $\mathrm{i}$ nedläggningsdrabbade bruksorter - med början i Vikmanshyttan, Dalarna, 1977 - där de berörda fick stöd då det gällde att $\mathrm{i}$ utställningsform presentera sin syn på jobbet, arbetsgivaren och lokalsamhället. Alltså att animera en lokal opinionsbildning. - Animerande verksamhet har aldrig blivit något livskraftigt inslag i museiverksamheten.

Framför allt länsmuseerna ökade under perioden sin produktion av regionala vandringsutställningar, en verksamhet som fick större volym omkring 1970.

Insikten om sambandet mellan natur 
20 och kultur resulterar i några få nya tjänster för naturvetare på länsmuseerna och strävan att kombinera de två i basutställningar, t.ex. på Upplandsmuseet.

Till perioden hör också tillkomsten av SAMDOK, sammanslutningen av kulturhistoriska museer för dokumentation av samtiden. Idén kan ses som en renässans för föremålsinsamlingen (i begynnelsen var det bara tal om ting, ej data) - och kanske för tidens utvecklingsoptimism.

Med några års fördröjning börjar nu den positivistiska, faktainrikatde utställningmodellen vika för ett koncept med heurismens inlevelse och forstaelse som huvudmoment (även om det didaktiska förvisso inte negligerades). Några milstolpar är de av Anders Åberg formgivna Land du välsignade (Riksutställningar och Nordiska museet 1973, för produktionen svarade bl.a. Åberg, Eva Lis Bjurman och Eva Persson) och Människor kring en verkstad (Stadsmuseet 1975, producerad av Magnus Adelcreutz) samt vidare Nordiska museets jubileumsutställning Svenskens hundra år (1973, producent Bengt $\mathrm{Ny}$ ström). Stark upplevelse och debatt väcker Riksutställningars Maskin makt (1977), producerad av Eva Persson, ${ }^{8}$ där framför allt det helvetiska ljudet från vävstolarna blir en slagkraftig kritik mot arbetsmiljön. Kritiken gällde också alienationen och «arbetets degradering» (Braverman).

Inte bara inom hantverk utan också på industriella arbetsplatser finns en handens kunskap, en kunskap som man på 70-talet önskade rädda vad gäller nyligen nedlagda industrier. Flera sådana, med bevarade maskiner, övertogs av intresserade lekmän och en ny museikategori uppstod: arbetslivsmuseer. Först ut torde ha varit Remfabriken i Göteborg. Med hjälp av tidigare anställda kunde produktionsprocessen återupplivas och förevisas.

Betydelsefull för den allmänna kulturhistoriska utställningsgestaltningen en halv generation framöver blir Västerbotten museums basutställningar från 70-talets början, formgivna av Göran Carlsson i samarbete med (och delvis inspirerade av) Anders Åberg. Konstnärligt byggda byggnads- och landskapsmodeller, inte slaviska efterapningar utan formgivna som en syntes, vidare dioramor, videovisningar, rumsrekonstruktioner, naturinslag m.m. bildar en föremålsrik, "tät» helhet. Konceptet kan sägas bestå av upplevelseskapande storskaliga element som integrerats med visualiserade didaktiska avsnitt samt aktivitetsprogram. Det kom framgent att utgöra en ofta utnyttjad inspirationskälla för kulturhistoriska basutställningar i svenska museer.

Mot slutet av decenniet, i dec. 1978, arrangerade Statens kulturråd och Svenska museiföreningen en stor konferens på Utö, till vilken utgavs ett diskussionsunderlag, som tog upp museernas kulturpolitiska roll. Skriften får anses som ett försök att anpassa institutionerna till den del av rådande tidsanda som rörde kulturinstitutionernas öppenhet. Häftet kom också att tjäna som studieunderlag för personal och styrelse vid många museer."

Den museala verksamheten under 70talets senare del var alltså påverkad av 1974 års kulturproposition, som fått genomslag $\mathrm{i}$ tidsandan. Museiverksamheten och den kulturpolitiska debatten var vital. Stora utställningsprojekt med upplevelse som huvudtema anslöt till det vetenskapsteoretiska paradigmskifte som påbörjats tio år tidigare och nu fått genomslagskraft. 
V

Vi förflyttar oss ytterligare ungefär tio år framåt, till yuppietidens kulmen och plötsliga ekonomiska nedgång med nedskärning av museianslagen som följd, högerbölja och "den svenska modellens» sammanbrott. Det traumatiska Palmemordet präglar hela nationen. Arbetslösheten ökar dramatiskt. Skillnaden mellan rik och fattig förstoras, tvåtredjedelssamhället skymtar. På det internationella planet märks framför allt kommunismens implosion med Berlinmurens fall 1989 samt Tjernobyl- och aids-katastroferna. Fundamentalism, nyreligiositet, stort intresse för kropp och hälsa och starkt ökad ström av flyktingar är andra stickord.

Också under denna period tillkommer en museiutredning, nu koncentrerad på de centrala museernas uppgifter och ansvar för landets museiväsen. Utredningen sker internt på statens kulturråd. En av de drivande krafterna är Erik Hofrén. Tre rapporter framläggs 1986, bl.a. Museiforslag. Där lanseras idén om basmuseer, i den efterföljande propositionen omdöpta till ansvarsmuseer. De fem utpekade skall, kort sagt, fungera som pådrivare och serviceorgan inom resp. museisektor. Vissa utvecklingsprojekt lanseras också och sjösätts senare i form av utställningar och verksamheter: nya perspektiv på den svenska historien, Sverige och tredje världen samt ekologisk kunskapsspridning - aktuella ämnen "hämtade» från tidsandan. Museernas anpassning i detta avseende centraldirigeras alltså, staten lägger förhållandena tillrätta för en kollektiv kraftsamling. En ny situation!

Perioden kännetecknas till någon del av «konservatism», ett återvändande från ett hejdlöst utställande till de traditionella basuppgifterna dokumentation, vård och förbättrad katalogisering (genom ADB). Tendenserna skall blomma ut i mitten på 90 talet efter den då framlagda utredningen Minne och bildning. Museernas uppdrag och organisation..$^{10}$ Några hårdare krav på effektivitet och rationalisering finns ännu ej, också dessa kommer med nyssnämnda utredning.

Museiverksamheten under 80-talets senare del har knappast samma starka samhälleliga aktualitet som i de två andra behandlade perioderna - eller är det en felsyn på grund av det korta tidsavståndet?

Jag menar att min genomgång dokumenterat att museerna - åtminstone de beskrivna museerna - visar god följsamhet när det gäller anslutning till tidsandan. Det skall dock framhållas att det ännu inte undersökts hur den stora massan av museer anpassat sig. Jag tror mig dock tryggt kunna säga att medvetenheten tilltagit jäms över, konstigt vore det eljest. Likaså har aktualiteten i utställningarna ökat. Museerna har till fullo tagit sitt ansvar och integrerats i samhället.

\section{NOTER}

1. Om dessa se G. Rosander, Landskapsförändring och kulturhistorisk dokumentering. Riksantikvarieämbetets etnologiska undersökningar. (Festskrift till Sverker Janson. Stockholm 1988. [Maskinskr.])

2. Lektorerna har tillsammans med Hvarfner redogjort för de första årens verksamhet i ett temanummer av Svenska Museer om länet (1966:3).

3. S. Beckman, Tidsandans krumbukter. Stockholm 1983. [Maskinskr.] (Sekretariatet för framtidsstudier) - Från Svenska Akademiens ordboksredak- 
tion i Lund har jag fått ett antal excerpter om 'tidsanda'; några har använts här.

4. Om ideologier. (Om ideologi och ideologianalys. Utg. av S.-E. Liedman \& I. Nilsson. 2 uppl. Göteborg 1989.)

5. Jamför Staffan Carléns arbete Att ställa ut kultur. Om kulturhistoriska utställningar under $100 \mathrm{ar}$. Stockholm 1990. (Acta Ethnologica Umensia. 3.)

6. Antikvitetsutredningen har beteckningen SOU 1965:10. MUS 65's delar heter Kulturminnesvard (SOU 1972:45), Museerna (SOU 1973:5) och Utställningar (SOU 1974:43).

7. Skildringen - som naturligtvis skall ses som en partsinlaga - grundar sig på brev från Lagercrantz till förf., utförligt refererat i G. Rosander, Museet som opinionsbildare. («Museernas väsen.» Tre forredrag vid Göteborgs museikollegium 1985.12.10. Göteborg 1986. [Maskinskr.]) Jfr även B.

Lagercrantz, Sju stormiga år (Stadsvandringar. 11. [1988]. - Också andra, här återgivna händelser är hämtade ur min artikel (med källförteckning), där de delvis är mer utförligt behandlade.

8. Om utställningen se Eva Persson, Utställningsform. Stockholm 1994, s. $69 \mathrm{ff}$.

9. G. Rosander, Samla, vårda, visa - eller något mer? Om museernas kulturpolitiska roll. [1 uppl.]

[Stockholm] 1978. - Skriften tillkom efter ingående diskussion med konst-, musei- och utställningsnämndens ordf. Sten Rentzhog.

10. SOU 1994: 51. Refererad i Nordisk Museologi 1995:1.

\section{SUMMARY}

Museums and the spirit of the time

Some of the changes in museum activities in Sweden from the 1940s and onwards are examined and related to the changes in the general spirit of the time. The present structure of the Swedish museum system was established around 1940, with the setting up of a state-supported regional museum in each administrative region $(\mathrm{län})$. It is noted that a generation shift took place among the directors of regional museums in the 1960s and that a renewal started then which foreshadowed the ideas expressed in the cultural policy officially adopted in 1974. In fact, a new Swedish museology dates to 1962, when Harald Hvarfner was made director of the northernmost regional museum in Luleå. He introduced a professional museum education programme and started a decentralisation of museum activities with itinerant exhibitions and close cooperation with the local history associations in the municipalities of the region. His initiatives became the model for many young directors and together they argued for the ideas in a book, A Museum for the Seventies, opposing the declared aims of a contemporaneous State committee working on a report about museums. The open, many-splendored museum of their dreams was very much attuned to the new cultural policy, where freedom of expression was promoted in all cultural fields. The controversial effects became especially apparent in a series of exhibitions produced by the newly formed 'Institute for Itinerant Exhibitions' (Riksutställningar) and in the activities of the Municipal Museum of Stockholm. Ecological issues, the problems of underdeveloped countries and the like dominated the exhibition programmes and every effort was made to attract a wider public; the museums tried to become open 'houses of culture'. Positivism was replaced by a hermeneutic approach focussing on the human aspect in the interpretation of objects. In the $80 \mathrm{~s}$, it is noted, there has been an apparent return to what many curators have perceived as neglected areas of museum work conservation, care and the management of the collections.

Göran Rosander var sedan 1986 forrstekonservator (intendent) vid Norsk Etnologisk Gransking, Oslo. Aren 1980-86 var han docent och tf professor i europeisk etnologi vid Uppsala universitet, 1970-78 knuten till Nordiska museet och den ledande konstruktören av det stora SAMDOK-projektet. 